\title{
NARRATIVAS SOBRE PROCESSOS EDUCATIVOS NO SANTO DAIME
}

\author{
Ana Paula Kahmann \\ Éder da Silva Silveira
}

\section{Resumo}

O presente artigo contempla aspectos de uma pesquisa maior a respeito dos processos educativos ocorridos no interior de uma religião ayahuasqueira, o Santo Daime. O objetivo, aqui, é compreender como esses processos educativos são apreendidos e narrados por atuais e/ou antigos frequentadores dessa religião. Metodologicamente, trata-se de uma abordagem qualitativa que, além de pesquisa bibliográfica, utilizou-se de entrevistas semiestruturadas com sete sujeitos em diversas igrejas do CEFLURIS localizadas no estado do Rio Grande do Sul. Entende-se que os adeptos percebem o Santo Daime como um equivalente funcional da escola, cuja organicidade ou funcionamento estaria associado a um trabalho ritual e a um trabalho de transformação de si baseado no autoconhecimento. Para esses sujeitos, os rituais se constituem em determinados saberes considerados por eles essenciais.

Palavras-chave: educação; Santo Daime; processos educativos.

\section{NARRATIVES ABOUT EDUCATIONAL PROCESSES IN SANTO}

\section{Abstract}

The present article contemplates aspects of a larger research about the educational processes that occurred inside an ayahuasqueira religion, Santo Daime. Santo Daime is understood by its patrons literally as a school. The goal here is to understand how these educational processes are seized and narrated by current and / or former patrons of this religion. Methodologically, it is a qualitative approach that, in addition to bibliographic research, used documentary research in some hymnals, as well as semi-structured interviews with seven subjects attending or attending Santo Daime in several churches of CEFLURIS located in the state of Rio Grande do Sul. It is understood that adherents perceive Santo Daime as a functional equivalent of the school, whose organicity or functioning would be associated with a ritual work and a work of selftransformation based on self-knowledge. For these subjects, the rituals are constituted in certain knowledge considered essential by them.

Keywords: education; Santo Daime; educational processes.

\section{NARRATIVAS SOBRE PROCESOS EDUCATIVOS EN SANTO DAIME}

\section{Resumen}

El presente artículo contempla aspectos de una investigación más amplia sobre los procesos educativos que ocurrieron dentro de una religión ayahuasqueira, Santo Daime. Santo Daime es entendido por sus clientes literalmente como una escuela. El objetivo aquí es comprender cómo estos procesos educativos son incautados y narrados por los actuales y / o antiguos mecenas de esta religión. Metodológicamente, este es un enfoque cualitativo que, además de la investigación bibliográfica, utilizó la investigación documental en algunos himnarios, así como entrevistas semiestructuradas con siete sujetos que asistieron o asistieron a Santo Daime en varias iglesias de CEFLURIS ubicadas en el estado de Rio Grande do Sul. Se entiende que los adherentes perciben a Santo Daime como un equivalente funcional de la escuela, cuya organicidad o funcionamiento estaría asociado con un trabajo ritual y un trabajo de autotransformación basado en el autoconocimiento. Para estos temas, los rituales se constituyen en ciertos conocimientos considerados esenciales por ellos.

Palabras clave: educación; Santo Daime; procesos educativos. 


\section{INTRODUÇÃO}

A ayahuasca é uma bebida originária do Alto Amazonas. Provas arqueológicas mostram a existência do uso ritual na região há mais de cinco mil anos (SCHULTES, 1972). Mais de setenta grupos indígenas ainda a utilizam atualmente, "[...] tendo uma influência considerável em diversos aspectos da sua vida social e religiosa” (LUNA, 2005, p. 334). Ela é preparada a partir do cozimento de dois vegetais da floresta: o cipó jagube (Banisteriopsis caapi) e a folha chacrona, também conhecida como "rainha" (Psychotria veridis). O Santo Daime, que utiliza a ayahuasca em seus rituais, surgiu no estado do Acre, no início dos anos 1930, com o neto de escravos Raimundo Irineu Serra, chamado pelos seus seguidores de Mestre Irineu. São atribuídos à Rainha da Floresta, uma entidade relacionada ao chá, toda a estrutura e elementos dos rituais. Ela é quem teria dito para Irineu como proceder em relação à sua estruturação. Por isso, muitos seguidores se referem ao Santo Daime como "a escola da Rainha".

Atualmente existem diferentes grupos que podem ser identificados como Santo Daime. O CEFLURIS $^{1}$ inicialmente é uma dissidência do grupo denominado Alto Santo, e fundado pelo Mestre Irineu. Porém, as igrejas que se denominam Alto Santo são poucas, e restritas à cidade de Rio Branco (AC) e de Porto Velho (RO). Já o CEFLURIS tornou-se mais conhecido, e se destaca com um maior número de membros, expandindo-se pelas principais capitais do Brasil e para outros países. (LABATE, 2004, p.66-68). Atualmente existem cerca de 60 filiais fora do Brasil (SANTO DAIME, s. d, s. p.), em pelo menos 43 países $^{2}$. E a visão dos rituais do Santo Daime como uma escola é amplamente difundida entre todos os seus participantes (ALBUQUERQUE, 2006, 2011B, 2012B; LABATE, 2004; OLIVEIRA, 2008; KAHMANN; SILVEIRA, 2017).

O presente artigo é decorrente de uma pesquisa maior e visa compreender como os processos educativos são apreendidos e narrados por atuais e/ou antigos frequentadores dessa religião. Metodologicamente, parte-se de uma abordagem qualitativa que se enquadra em um paradigma interpretativo, de natureza qualitativa. Existem atualmente nove igrejas do Santo Daime no Rio Grande do Sul, filiadas ao CEFLURIS. A pesquisa foi realizada com fardados, ex-fardados e visitantes, que apesar de residirem em um mesmo município, frequentam ou frequentaram essas diversas igrejas. Os fardados não são filiados a uma igreja específica, mas sim ao CEFLURIS, não sendo possível precisar o número exato de adeptos em cada uma delas. Isso também ocorre pelo fato do intenso intercâmbio entre as igrejas no estado. Muitos fardados, inclusive, vão residir em outras cidades para auxiliar as igrejas que necessitam, ou devido à constituição de laços de afetividade com outras comunidades.

Conforme acordado inicialmente com os sujeitos colaboradores, eles tiveram seus nomes preservados, criando para si um codinome. Para tentar abranger da melhor forma possível a heterogeneidade de indivíduos que frequentam essas igrejas e suas mais variadas percepções a respeito do tema, delineou-se que o grupo de entrevistados deveria constituir-se de pessoas com diversas idades, classes sociais, funções dentro dos rituais e níveis de contato com o Daime. Dessa forma, o grupo de entrevistados foi constituído por sete pessoas, contando, assim, com quatro mulheres e três homens, que adotaram os seguintes codinomes: Cássio, Helena, Laudemiro, Maria, Morgana, Paulo e Stela. Os sujeitos também foram escolhidos conforme sua disposição em colaborar com a pesquisa. Até porque um daimista contatado se recusou a dar entrevista declarando que: “O

\footnotetext{
1 O CEFLURIS (Centro Eclético da Fluente Luz Universal Raimundo Irineu Serra) é uma linha do Santo Daime fundada por Sebastião Mota de Melo, conhecido como Padrinho Sebastião.

2 Disponível em: <www.santodaime.org/site/institucional/nossas-instituicoes/iceflu > Acesso em: 15 dez. 2015.
} 
Santo Daime se vive e não se racionaliza" e que "muitas vezes meio copo de daime ensina mais que uma universidade inteira".

\section{OS PROCESSOS EDUCATIVOS DO SANTO DAIME}

Como os rituais do Santo Daime são entendidos por seus frequentadores como uma escola, essa ideia encontra-se, também, nas pesquisas de Maria Betânia Barbosa Albuquerque (2006; 2007a; 2007b; 2011a, 2011b; 2012a; 2012b) e de José Erivan Bezerra de Oliveira (2008). O último considera tal afirmação como uma caracterização metafórica dessa religião (OLIVEIRA, 2008, p. 115). Porém, na fala dos sujeitos aqui entrevistados, aparece o entendimento dos rituais como um processo educativo que traria conhecimentos tão ou mais importantes que os aprendidos nas escolas oficiais, onde se desenvolve a denominada educação formal. Portanto, na visão da maioria dos entrevistados, o Daime é uma escola, sendo essa palavra usada em seu sentido literal e não como uma metáfora. O Santo Daime é por eles considerado uma escola espiritual que ensina o autoconhecimento, o que se refletiria em uma vida melhor; enquanto a escola oficial é considerada uma escola material. Vale ressaltar, aqui, que o espiritual é entendido como "o reino da verdade" e o material como o "mundo de ilusão". Cemin, doutora em Antropologia Social pela USP, também defende que o termo escola no Santo Daime não é metafórico:

No "Cruzeiro" o termo escola não é metafórico, como poderíamos crer, presos a nossas próprias estruturas mentais que nos acostumam a reconhecer como "real" aquilo que identificamos como legítimo, nesse caso, o sistema oficial de ensino. Ocorre, entretanto, que Irineu é Mestre Ensinador, sua "missão" é uma "escola" para o ensino espiritual (CEMIN, 2005 apud ALBUQUERQUE, 2011b, p. 170).

Durante todo o trabalho ritual (exceto algumas orações na abertura e no encerramento) são entoados hinos, que são cânticos religiosos atribuídos a entidades divinas. O hinário "O Cruzeiro" foi "recebido" por Mestre Irineu e é considerada a base dessa religião. Nele, é grande a recorrência de palavras que remetem a ensino (ensina, ensinou, ensinar, ensinos, ensinador). Nesse conjunto de hinos é afirmado que Irineu é um professor e que aprendeu o que sabe, principalmente, com uma entidade feminina. Essa entidade feminina, que lhe ensinou o que ele precisava para fundar essa escola espiritual, é geralmente referida como Rainha da Floresta ou Virgem Mãe. De seus aprendizados diretos com a Virgem Mãe é que viria a sua legitimidade como professor, como se pode observar na seguinte estrofe do hino Aqui estou dižendo: "A virgem mãe é soberana/ Foi ela quem me ensinou/ Ela me mandou prá cá/ Para ser um professor” (O Cruzeiro, hino n.125). O mesmo pode ser subentendido na estrofe do hino Cantar ir. "A virgem mãe me deu/ O lugar de professor/ Para ensinar as criaturas/ Conhecer e ter amor" (O Cruzeiro, n.28). Já nos hinários de Sebastião Mota, Irineu é referido diversas vezes como "Mestre Ensinador", e teria sido diretamente dele que Sebastião teria recebido a legitimidade para dar continuação aos trabalhos dessa escola, ensinando aos que interessarem.

Uma das questões do roteiro de entrevista indagava: o Santo Daime pode ser considerado um processo educativo? Todos os entrevistados afirmaram que sim. Sintetizando os temas centrais das respostas, eles afirmaram que o Santo Daime se trata de um processo educativo porque possibilita o autoconhecimento, uma ressignificação do passado, uma transformação do ser, uma libertação, o conhecimento de outras culturas e por formar um ser humano melhor. Todos esses aspectos aqui relatados são considerados pelo conjunto dos sujeitos como ausentes na educação formal promovida pelas escolas, já que essas visariam a padronização do ser. Como relata Helena 
“[..] a escola não te traz autoconhecimento. A escola impõe a norma. Tu tens que ser igual!” Ao contrário, o Santo Daime é entendido pela totalidade desses sujeitos como um aprendizado extremamente pessoal, que é vivido diferentemente de uma pessoa para outra. É possível visualizar na fala de Paulo este contraste que emerge nas narrativas dos entrevistados:

Cada ser humano é um ser diferenciado. Então, não existe como padronizar uma educação. Na escola não existe liberdade de expressão. Não existe espaço para a individualidade. [...] E aí está a grande diferença para o Santo Daime, que [...] não obriga nada. Não proíbe nada. Ele só mostra aquilo que você está fazendo. E as consequências. [...] E a escola de hoje, terrena, não trabalha assim. O trabalho é do tipo:- Você está aqui, você tem que fazer isso e está acabado!!!- Não ensina na profundidade, não ensina no lado humano. É só cognitivo, cognitivo e cognitivo. É tudo robótico e não tem o que fazer. [...] E aí vêm as doenças. Porque tem muitas pessoas que não aceitam isso, essa padronização. Vem! Vem rebeldia, vem depressão, vem um monte de coisa. É sério! (PAULO).

Como se pode perceber nas narrativas, o aprendizado no Santo Daime seria individualizado e apresentaria um caráter de imprevisibilidade. O próprio sujeito em si nunca teria uma vivência igual à outra. A questão de que a aprendizagem no Daime seria sempre única e individual, diferentemente da escola, é descrita da seguinte maneira por Stela:

O Daime é diferente da escola. Porque na escola oficial é aquela matéria pra todos. O chá ele vai te dar aquela matéria que tu precisas. Nunca vai te dar mais que aquilo que tu podes aprender. São matérias diferentes que passam. [...] Muitas vezes as pessoas bebem a mesma quantidade do chá e tem experiências completamente diferentes. Então, é muito pessoal. É assim de cada um, apesar do ritual ser igual pra todos. Visualmente é padronizado, mas internamente é bem pessoal (STELA).

A questão: “[...] esses ensinos teriam algum objetivo?” foi afirmativa por unanimidade. Os principais tópicos extraídos das respostas foram que os objetivos eram proporcionar aos seres: autoconhecimento, autoconsciência, uma vida melhor, tornarem-se pessoas melhores, aperfeiçoamento, cura, "sair das caixas", libertação, paz, autodisciplina e visão da totalidade. Como afirma Helena: "O objetivo desse ensino é sair das caixas! É uma doutrina que vai trazer uma visão inovadora [...] de sobreviver em meio a esse caos que é a nossa realidade humana. Realidade essa cheia de contradições" (HELENA). A visão de que o Santo Daime traz um ponto de vista "totalmente novo" para a pessoa, muito além das convenções sociais, é outro aspecto que permeia a fala dos entrevistados. Esse "novo olhar" trazido pelo Daime estaria relacionado, de uma forma ou de outra, a todos os outros tópicos listados em relação aos objetivos desse ensino. Isso porque, de acordo com a maioria dos entrevistados, no "mundo de ilusão", onde se percebe somente a dimensão material, não seriam proporcionados esses aspectos. Poder-se-ia dizer, em outras palavras, que encaixotados nas verdades e no modo de ser de uma sociedade racional materialista, questões como visão da totalidade, autoconsciência, autoconhecimento e libertação, não seriam possíveis.

O que os entrevistados apontaram como uma "nova perspectiva", que possibilitaria "sair das caixas", trazendo "um novo olhar sobre o ser e o mundo" viria, segundo eles, pelas mirações e pelas peias. As mirações e as peias foram apontadas por uns como o ensinamento em si, e por outros como uma "metodologia", ou a forma como o Daime ensina. A esse respeito, Maria colocou que: "Elas trazem aprendizados! Trazem aprendizados sempre! Tanto a chamada peia quanto a miração!" Corroborando essa afirmação, Albuquerque (2011, p. 173) declara que “[...] é no estado 
de expansão da consciência, também chamado miração, que muitas aprendizagens se efetivam". Alguns também usaram a expressão insights para referirem-se a determinadas vivências por eles consideradas como desencadeadora de saberes. Foi salientado diversas vezes pelos sujeitos que o Daime ensina mostrando, e que ele mostra através das mirações, peias e insights. Laudemiro declara o seguinte a respeito das novas perspectivas mostradas pelas mirações:

Para mim as mirações são educativas no sentido de que elas te levam a um estado de percepção, de visão. Elas te mostram as coisas de uma nova forma. [...] É outra percepção. É um olhar diferente daquele que normalmente tu tens. São mostradas muitas coisas assim. Com uma nova ótica. [...] A partir do momento em que as mirações me mostram que existe outra forma de olhar, que existe outro lado, isso aí já é uma coisa importante. Então aquelas verdades que nos foram ditas, vemos que não são totalmente verdadeiras. Não! Existe outra coisa. E isso aí já é um aprendizado. [...] E agora quem vai decidir, basicamente, és tu. Tu vais ver o que tu queres: aqui ou ali. Tu tens a liberdade, como ser, de escolher. [...] E muitas vezes toda a nossa formação e educação é: Assim que é certo! Isso aqui que é certo! A ciência. E muitas coisas já estão caindo: Não! Não é bem certo! [...] Então é esse processo do aprender (LAUDEMIRO).

De acordo com o proposto na literatura referente ao Santo Daime, a miração é como os daimistas denominam o estado de êxtase produzido pela ingestão ritual da bebida. Clodomir Monteiro da Silva (1983) afirma que a palavra vem do espanhol, já que remete a "mirar", que em português significa olhar ou ver. Portanto esse termo passa a significar, no Santo Daime, as visões produzidas nos rituais e entendidas como "revelações" divinas ou espirituais (SILVA, 1983 apud GOULART, 2004, p. 10). Franca (2011) também relaciona as mirações às visões proporcionadas pelo Daime: "Alterações visuais são muito típicas e bastante conhecidas por seus usuários, sendo chamada de miração" (FRANCA, 2011, p. 90). Porém, Rehen (2007) e Alberto Groisman (1999) não restringem as mirações às visões. Para Rehen (2007, p. 124), "[...] apesar do termo 'miração' remeter a uma ideia de fenômeno visual como 'miragem', esta categoria nativa tem relação com diversos tipos de sensações que incluem a audição, o olfato e o tato". Já Groisman (1999, p. 55) declara que ela é, para os daimistas, "[...] o estado de consciência onde é possível ter contato com a espiritualidade ou percebê-la. Ela se manifesta através de um conjunto de percepções que proporcionam a sensação de transcendência". O autor salienta que a miração pode manifestar-se de diferentes formas:

[...] pode ser uma visão, ou seja, uma visualização de imagens celestiais, sons ou cheiros que não fazem parte da situação em que se está; pode ser uma introdução num outro universo, onde transitam seres de natureza desconhecida; pode ser o percurso dentro de uma planta ou animal da floresta; pode ser uma experiência cognitiva, na qual a mensagem está em forma de ensinamento do mestre (GROISMAN, 1999, p.55-56).

É possível perceber, nas narrativas, que os entrevistados também não relacionam, necessariamente, a miração à visualização, mas afirmam que a miração é o aprendizado, e que esse poderia vir por outras vias sensoriais. Esse é o caso de Maria, que afirma: "Eu sou de ouvir, de escutar. Não tenho mirações como as que são relatadas: -Ah! Eu vi tal lugar! De ver mesmo, de materializar. [...] O que não deixa de ser miração" (MARLA). Na miração, no ponto de vista desses entrevistados, estariam incluídos, por exemplo, peias, insights, intuições, sentimentos, pressentimentos, emoções ou escutar uma voz interior que indica algo. Todos esses seriam canais de ensinamento que não englobariam necessariamente a visão, já que os saberes no Daime viriam de diferentes formas, dependendo do tipo e do grau de mediunidade (abertura ao mundo espiritual) 
da pessoa em questão. Então, quando os entrevistados afirmaram que o Daime os mostrou alguma coisa, não se referiram exclusivamente ao mostrar através da visão, englobando, também, os insights e as peias.

A palavra insight, conforme o doutor em psicologia e psicanalista Marcos Chedid Abel (2003, p. 22), é encontrada com muita frequência na literatura psicanalítica, muitas vezes sendo traduzida para o português como “[...] compreensão interna, compreensão súbita, apreensão súbita, visão súbita, discernimento, perspicácia". Por insight os sujeitos referem-se aos "estalos", ou seja, aos momentos de iluminação ou de compreensões súbitas que foram relatadas como provenientes do trabalho ritual, porém, se estendendo para além desse. Paulo afirma que eles ocorrem com certa frequência: "[...] esses ensinamentos e esses conhecimentos vêm. Orientações vêm o tempo todo nos trabalhos e posteriormente, também, no dia a dia. Esses insights, esses estalos que acontecem" (PAULO). Da mesma forma que Paulo, Helena também afirma que os insights podem ocorrer fora do processo ritual: "[...] dentro do conceito que eu acredito que sejam as mirações, eu acho que elas podem vir durante o chá e após o chá, né? Através do teu subconsciente. Te dando insights e te conectando com o presente" (HELENA).

$\mathrm{Na}$ língua portuguesa, peia significa chibata ou chicote. Pode também ser entendida como algo com que se prende as patas dos animais, sendo utilizada figurativamente como obstáculo. ${ }^{3}$ Conforme Fernandes (1986, p. 133) e Goulart (1996, p. 42), a peia é definida, no contexto daimista, como uma "surra". Isso porque ela é considerada um castigo aplicado pelo Daime, que é visto como um "ser divino" que possui vontade própria (GOULART, 1996, p. 42). Leandro Okamoto da Silva (2004), que pesquisou sobre a peia daimista em sua dissertação, a tratou, similarmente, como um "castigo simbólico". De acordo com o pesquisador, os daimistas chamam de peia os efeitos considerados não agradáveis decorrentes da ingestão do Daime. Elas podem se manifestar de diversas maneiras: através de mal estar físico, como diarreias, vômitos, tontura; e mal estar psíquico, como confusão mental e visões aterradoras.

Para alguns dos sujeitos entrevistados, assim como a miração é entendida como o contato com o nosso Eu Superior ou com os planos superiores, que pode ocorrer através dos diversos sentidos do nosso corpo, a peia seria o contato com os planos inferiores através desses mesmos sentidos. No entanto, a maioria dos participantes considerou a peia como um exame de consciência e relacionada à miração. Como expõe Cássio: "[...] a peia é uma miração de alguma coisa que você fez e que não era correto". Contudo, ela é tida como benéfica, pois há uma compreensão do seu motivo, através de uma associação da reação sentida pelo sujeito com alguma má conduta que teria originado a peia. Por geralmente promover alguma mudança de hábitos e comportamentos, a peia é considerada uma ferramenta do processo de autoconhecimento ou de conscientização. Fernandes (1986, p.134), Dias Júnior (1992, p. 116) e Silva (2004, p.122) afirmam, assim como os sujeitos entrevistados, que a peia seria fundamental no processo de aprendizado realizado no Santo Daime.

Para que haja um processo educativo precisa haver um aprendizado. Quais aprendizados ocorrem no Santo Daime? O que se aprende? Maria Betânia Barbosa Albuquerque, em seu livro Epistemologia e saberes da ayahuasca (2011b), realiza uma síntese da sua pesquisa de pós-doutorado. Conforme a autora, o livro se direciona "[...] para os saberes corporificados na experiência educativa mediada pela ayahuasca, bem como para as bases epistemológicas que assentam tais saberes" (ALBUQUERQUE, 2011b, p.25). Para refletir sobre "[...] os saberes da ayahuasca vivenciados no contexto da religião do Santo Daime" (ALBUQUERQUE, 2011b, p. 163), a pesquisadora utilizase da bibliografia existente sobre a religião, dos hinários, e de entrevistas, quando indaga a daimistas de diversos países: “[...] o que você aprendeu com o daime?” (ALBUQUERQUE, 2011b, p. 163).

${ }^{3}$ Disponível em: http://michaelis.uol.com.br/busca?r=0\&f=\&t=\&palavra=peia. Acesso em 21 set. 2016. 
Dentre as categorias de saberes provenientes dessa investigação estão os saberes estéticos, saberes existenciais, saberes da paz e saberes de cura.

Os ensinamentos advindos da experiência e/ou da vivência são importantes para compreender os processos educativos no Santo Daime. Durante a análise, porém, entendemos que essas categorias não poderiam ser tratadas como sinônimos em relação ao Santo Daime. A experiência, apesar de ser um termo polissêmico, é geralmente entendida na área da educação como produtora de saberes. Mas o fato é que a experiência é uma categoria ocidental que não dá conta do modo de conhecer e da produção de saberes em alguns contextos. Diversos filósofos, como por exemplo, Dewey $(1959 ; 1976)$, defendem que uma experiência para ser educativa tem que ser reflexiva. Assim, o que diferenciaria a experiência da vivência (algo meramente vivido), seria um componente intelectual, a reflexão, que provocaria no sujeito um deslocamento de si, ou seja, uma transformação. A vivência é corazonada, ou seja, inclui juntamente com a razão o coração (GUERRERO ARIAS, 2012) e é, portanto, sentipensada. A crença na unidade original entre partetodo, humanidade-divindade, singular-universal, leva Dilthey, por exemplo, a entender a vivência como uma "[... experiência plena e não mutilada da realidade igualmente plena e total" (AMARAL, 2001, p.1). Conforme Amaral (1987, p. 135), o homem é, para Dilthey, o "[...] único ser que tem consciência da sua vida ao mesmo tempo enquanto parte e enquanto todo". A vivência é, nesse sentido, reviver a ligação com o todo, é uma religação com o espírito do absoluto. "É o modo humanamente limitado de manifestar ou exteriorizar o compromisso original com a unidade espiritual, com o universal" (AMARAL, 1987, p.137). A vivência é que, portanto, seria realmente transformadora e educativa, por conter também a dimensão espiritual e não se reduzir a um componente intelectual. Como afirma Guerrero Arias (2012, p. 205), o saber meramente cognitivo não tem o poder de comprometer nossa subjetividade e, desse modo, transformar a existência individual ou coletiva. A vivência, portanto, foi uma categoria mais adequada para se referir ao modo de produzir saberes no Santo Daime, sobretudo se considerarmos os casos de miração e de peia.

Assim sendo, diversas pesquisas tratam das transformações declaradas pelos frequentadores do Santo Daime como decorrentes do uso ritual da ayahuasca e as respectivas mirações. Felipe Starling Loureiro Franca (2011), na sua dissertação de mestrado em Psicologia, entrevistou cinco pessoas que utilizam ayahuasca há pelo menos dez anos. No item intitulado "A ayahuasca me trouxe" ele categoriza as transformações vividas ao longo do tempo por seus entrevistados em: mudanças na visão de mundo; redefinição de valores; crítica à sociedade; mudanças de atitude e comportamento; amadurecimento psicológico; maior conexão com a natureza. Franca explica que a mudança na visão de mundo dos seus entrevistados está intrinsecamente ligada a uma redefinição de valores e prioridades que acarretaram no desenvolvimento de um olhar crítico em relação aos padrões sociais capitalistas, e também em uma mudança de atitude e de comportamento (FRANCA, 2011, p. 114-116). Já Isabel Santana de Rose (2005) entrevistou, para a sua dissertação em Antropologia Social, profissionais da saúde que participam do Santo Daime. Esses profissionais também relataram transformações provenientes dos rituais:

Além das mudanças na profissão, as pessoas relatam mudanças também na sua vida como um todo. [...] perceberam um aumento em sua compreensão, na sua paciência, na sua capacidade de amar e na sensibilidade. Também relatam uma expansão da consciência e o desenvolvimento da mediunidade (ROSE, 2005, p. 114). 
A dissertação de Sérgio Alex Silva Lima (2005), em Ciências da Religião, teve como foco as “[...] transformações existenciais mencionadas como decorrentes do contato com o universo simbólico da doutrina do Santo Daime" (LIMA, 2005, p.2). Conforme Lima, seus colaboradores afirmaram que o contato possibilitado pelo Daime com o plano espiritual da existência trouxe uma ressignificação de sentido para o viver. As transformações descritas seriam similares ao conceito de metanoia, definido pelo autor como uma "transformação de sentimentos" (LIMA, 2005, p. 97). Por fim, ele conclui que as vivências com o Santo Daime "[...] têm potência para instaurar transformações significativas e duradouras, relacionadas à percepção de mundo, de si mesmo (valores, hábitos, costumes etc.) e do outro (família, sociedade)" (LIMA, 2005, p. 98).

Já em relação aos sujeitos entrevistados para essa pesquisa, um ponto comum em suas falas é que essas transformações se relacionam a um trabalho sobre si mesmo onde os daimistas geram autoconhecimento. Esse trabalho de transformação de si estaria intrinsecamente relacionado ao trabalho ritual (onde ou a partir de onde ocorrem as peias e mirações). Como já visto o Santo Daime, ao entender seus rituais como um processo educativo, se autodenomina como uma escola. Ao mesmo tempo em que é percebido como uma escola, esses rituais são denominados de "trabalho". De acordo com MacRae (1992, p.91) essa terminologia também é utilizada por vegetalistas e em muitos centros espíritas. Como afirma Maria: "O trabalho em si ele é um aprendizado. Não tem como não aprender. Como eu te falei. Se a pessoa não vê ali na hora, no momento, não quer dizer que não tenha aprendido. Ela só não tem a consciência disso" (MARLA). $\mathrm{O}$ autoconhecimento promoveria a percepção de que o ser humano é formado por três dimensões: o Eu Superior, o Eu Inferior e o aparelho. Peláez (2004, p. 482), que pesquisou sobre o processo de "cura espiritual" no Santo Daime, explica da seguinte maneira essas dimensões:

O Eu Superior seria a dimensão espiritual do homem, a "memória divina", que mesmo sendo às vezes ignorada, todos a possuiriam e a qual se teria acesso através de "revelações". O Eu Inferior, conceito que se aproxima da noção de ego, estaria constituído pelos aspectos intelectuais, emocionais e sensoriais, diferentes em cada indivíduo. O aparelho seria o corpo do homem, em seus aspectos anatômicos e fisiológicos.

A ignorância de si mesmo seria identificar-se com o Eu Inferior, e desconhecer o Eu Superior. "Este indivíduo [...] estaria espiritualmente doente e, mais cedo ou mais tarde, o desequilíbrio manifestar-se-ia- como um sinal de alerta- na sua mente e/ou no seu corpo e, então, também adoeceria mental e/ou fisicamente" (PELÁEZ, 2004, p. 482-483). O entendimento espiritual revelado pelo contato com o Eu Superior é que traria a cura espiritual que se refletiria na matéria. Como declara Cássio: "Um simples entendimento já é uma cura bem grande. Às vezes entendemos bem pouquinho no espiritual, e na matéria se reflete em uma cura enorme para a vida inteira". Ao ser indagado se as curas sempre se relacionam com um entendimento de algo sobre si mesmo, o entrevistado respondeu:

Sim, sim! No meu caso as curas sempre vieram de um entendimento. Porque se a gente não aprender, se não tiver um entendimento, como é que a gente vai se curar? [...] Então, a gente consegue ter esses entendimentos e consegue se curar. Porque o entendimento é uma cura. A gente só se cura quando a gente entende. Senão a gente fica batendo a cabeça em ponta de prego, e nunca se cura porque não entende (CÁSSIO, grifos nossos).

Essa relação entre um entendimento sobre si mesmo (autoconhecimento) com a cura apareceu indiretamente na fala de todos os sujeitos. Essas insinuações levaram a acrescentar nas entrevistas perguntas similares a essa: existe alguma relação entre o autoconhecimento e a cura? E 
as respostas foram sempre afirmativas. Maria, por exemplo, afirmou no decorrer da entrevista: "O aprendizado é a cura. A gente se cura quando a gente sabe o que é que é" (MARLA). Ao ser indagada sobre uma possível relação entre o aprendizado e a cura, ela observou:

Quando alguém diz: -“Ah! Eu estou com uma doença." - Tu tens que curar a tua
alma. E quando tu tens a compreensão daquilo ali, tu vais aliviar. A tua alma vai
ter o conhecimento. Vai ter a cura. [...] Porque tem pessoas que dizem: - "Ah!
Teve uma pessoa que teve câncer e ela conseguiu se curar.” - Por quê? Porque
ela conseguiu compreender ao que é que levavam as suas amarguras e as suas
tristezas. Ela irá se curar se ela conseguir mudar esse padrão. [...] Até a gente
compreender isso, ficamos magoados ou nos chateamos. Aí começamos a
desenvolver ansiedade. Daqui a pouco já é uma depressão. Daqui a pouco dá
síndrome do pânico. É todo um processo de autoconhecimento (MARLA).

Ao "acessar" os ensinamentos revelados pelo Eu Superior, e colocá-los em prática, o daimista entraria em um processo de cura e libertação que duraria por toda a sua existência. Portanto, seria a autoconsciência dos processos produtivos internos, ou seja, a consciência de como o sujeito produz a si mesmo, que traria a libertação da identificação com o Eu Inferior, origem da ignorância que acarretaria sofrimentos e males. A essa ignorância que promove a identificação com o Eu Inferior, os daimistas chamaram de "mundo de ilusão". Esse processo de cura e libertação desencadeado no Santo Daime aproxima-se do que Jung (1987) chamou de processo de individuação, aproximações essas também apontadas nas dissertações de Dias Júnior (1992), Silva (2004), Lima (2005) e na monografia de Tavares (2005).

Conforme os termos propostos por Jung (1987), individuação é o processo no qual o ego (centro da zona consciente) começa a integra-se ao Si-mesmo, também denominado de Self (centro e totalidade da psique), ou seja, quando ao ampliar nossa consciência, vamos aos poucos transcendendo a nossa identificação com o ego, ele vai passando de nosso senhor a colaborador. Isso porque a função do ego não seria "[...] seguir ilimitadamente seus próprios impulsos arbitrários" (FRANZ, 2008, p. 213), mas, sim, auxiliar na realização da “[...] totalidade da psique. É o ego que ilumina o sistema inteiro, permitindo que ganhe consciência e, portanto, que se torne realizado" (FRANZ, 2008, p. 213). Sintetizando, o processo de individuação seria um processo de libertação da tirania do ego e realização do Si-mesmo.

Semelhante, também, é a narrativa do Baghavad Gita, texto reverenciado pelos hinduístas que conta a história de um príncipe, denominado Arjuna, que teve seu trono usurpado por seus parentes. Então, aparece-lhe Krishna, que o convence a iniciar uma batalha pela reconquista de seu reino. Conforme comentários inseridos no decorrer dessa obra, pelo seu tradutor ao português, Huberto Rohden, alguns iniciados como Rabindranath Tagore e Mahatma Gandhi

[...] interpretam as palavras de Krishna em sentido simbólico, como aliás toda luta de Arjuna contra os usurpadores, entendendo que Arjuna é o Eu humano cujo reino foi usurpado pelo ego e Krishna é o Eu plenamente realizado, que convida Arjuna a fazer a sua auto-realização, derrotando seus parentes- os sentidos, a mente e as emoções-, que, no homem profano, usurpam injustamente o domínio do divino Eu. E como essa reconquista só é possível pelo conhecimento da verdadeira natureza humana, os 18 capítulos do Baghavad Gita se resumem a uma extensa explicação do autoconhecimento humano, indispensável para a sua auto-realização (BHAGAVAD GITA, 2007, p. 17).

Desse modo, o entendimento dessa dinâmica interior seria a base do autoconhecimento. Mais adiante, no Baghavad Gita, o tradutor explica que o autoconhecimento deve estar ligado ao reto agir (naiskarman), que é defendido por Krishna como meio de libertação. O reto agir opõe-se 
ao falso agir (vikarman), quando se age por amor ao ego, o que é uma ilusão; e é definido como "[...] agir em nome e por amor ao Eu central” (BHAGAVAD GITA, 2007, p. 37), ainda que o ego sirva de veículo de expressão dessa fonte divina. Para que isso seja possível "[...] é indispensável que ele conheça intuitivamente o seu Eu central, que em sânscrito se chama Atman, nos livros sacros do cristianismo aparece como alma ou espírito, e na filosofia e psicologia ocidental é denominado Eu (Self, Selbst)" (BHAGAVAD GITA, 2007, p. 37).

Portanto, o chamado Eu Superior, no Santo Daime, pode ser entendido como o Self, de Jung, ou como o Atman dos hinduístas. Também pode ser relacionado com a palavra alma dos guarani descrita por Chamorro (2008), e o daimon descrito no livro O código do ser, de James Hillman (2001). Todas essas denominações referem-se ao Eu central. Já o Eu Inferior daimista é o ego junguiano, que em sânscrito se chama Aham. Também nessa religião brasileira fala-se em uma "batalha espiritual" de doutrinação das forças inferiores. Os trabalhos espirituais são "[...] concebidos como guerras ou batalhas contra a fraqueza, a impureza, a dúvida ou a doença. Os adeptos são os soldados ou os midam, que ao lado de Jura (Deus), formam o Império Juramidam, que dá forças aos obedientes, humildes e limpos de coração" (MACRAE, 1992). Como diz o trecho de um hino entoado pelos daimistas em seus rituais: "Estou dentro da batalha/ Sofrendo mas sou feliz/ Nela estou aprendendo/ O que eu ainda não sabia". ${ }^{4}$ Conforme Vergueiro (2008), Jung reconhece que algumas religiões podem exercer um papel considerável no processo de individuação, desde que elas não percam o sentido original de religiosidade. A autora esclarece que:

O sentido original de religiosidade, para Jung, pode ser esclarecido pela origem latina da palavra religare. Esta nos remete à capacidade humana de religar, reconectar dimensões da personalidade que tendem a um natural afastamento, especialmente na primeira metade da vida. Ou seja, a religiosidade é, para Jung, a capacidade de religar a dimensão do ego, centro do campo da consciência, à do si mesmo, totalidade psíquica. Uma vez desenvolvida e exercida essa religação, o ego pode realizar as demandas do si mesmo, que visam à individuação (VERGUEIRO, 2008, p. 128).

Vale salientar que, apesar da educação do Santo Daime ser entendida pelos sujeitos entrevistados como indissociada da "batalha espiritual", a intenção aqui não é limitar o processo educativo do Santo Daime ao processo de individuação de Jung. Isso resultaria em um reducionismo tanto das vivências educativas proporcionadas pelo Santo Daime, quanto dos conceitos anteriormente citados. Esse autor foi citado por fornecer ferramentas teóricas para a tradução e compreensão das narrativas daimistas em relação aos seus aprendizados, porque para os daimistas a educação espiritual e o trabalho espiritual, vistos como indissociáveis, é que permitem a libertação da identificação com o Eu Inferior, que originaria o "mundo de ilusão". E, aos poucos, em um processo que dura toda a existência, ocorre uma reconexão com o Eu Superior através de revelações diversas.

No Santo Daime, a maioria dos entrevistados também afirmou que se aprende em contato com a comunidade ${ }^{5}$. Nesse sentido, Paulo declara o seguinte a respeito da comunidade daimista:

A importância da comunidade é justamente ligada com aquilo que eu falei antes, do auxílio. Do auxílio com os irmãos. Aquele processo de autoajuda. Aquele processo de socialização. É um processo educativo de socialização, o que

\footnotetext{
${ }^{4}$ Hino n. 25 do hinário Lua Branca de Madrinha Rita.

5 O Santo Daime fomenta a criação de comunidades autossustentáveis que se instalam ao redor das igrejas. Mas comunidade pode se referir, também, ao grupo de frequentadores locais que criam laços de colaboração e afetividade entre si.
} 
significa caminhar junto, lado a lado. Um auxiliando o outro. Isso é um processo muito importante dentro da comunidade (PAULO).

Morgana, por exemplo, afirma: "No Daime tem muitas coisas que trazem aprendizados. Além dos hinos, do maracá, violão e canto, tem também a comunidade. [...] O simples contato com a comunidade já é um ensinamento". (MORGANA). Portanto os aprendizados são entendidos como processados tanto dentro dos rituais quanto fora. Essa percepção vai ao encontro da noção de endoculturação. Segundo Brandão (2007), endoculturação e socialização são maneiras pelas quais denominamos as formas comunitárias de se ensinar e aprender. Sendo assim, é o processo no qual o indivíduo ao socializar-se, inserido em uma cultura, vai aprendendo seus saberes, crenças ou hábitos, o que leva a afirmação de que "[...] todo saber é cultural” (ALBUQUERQUE, 2015, p. 654). Além de aprenderem com a comunidade, também afirmam que a vida é uma escola, ou seja, que estamos sempre aprendendo, afirmação que remete ao processo de socialização.

\section{CONSIDERAÇÕES FINAIS}

Para pesquisas de educação não escolar é preciso salientar a importância de assumir uma concepção da educação como domínio da cultura. Partindo dessa premissa, buscamos compreender nesse artigo como os processos educativos ocorrem e são narrados por atuais e/ou antigos frequentadores do Santo Daime. Da mesma forma que Kusch (2000), em relação aos saberes indígenas, os sujeitos dessa pesquisa também afirmaram que os saberes daimistas apontam para o ritual. São nos rituais que se constituiriam determinados saberes que transcendem o objeto e são considerados essenciais para uma vida melhor. Esses saberes, segundos os entrevistados, se dariam por revelações, ou seja, ensinamentos advindos das mirações e das peias. A ausência de revelação seria a ignorância que originaria, conforme a terminologia daimista, o "mundo de ilusão".

Do mesmo modo, todos os entrevistados afirmaram que no Santo Daime existe um processo educativo, mas que os aprendizados decorrentes desse processo seriam extremamente pessoais, pois seriam vividos diferentemente de uma pessoa para outra. Foram indicados pelos sujeitos que no Daime se aprende através dos trabalhos, dos hinos, das mirações, peias, insights ou pela convivência com a comunidade. Trabalho é a forma como os daimistas chamam seus rituais. Dentro dos trabalhos, diversos elementos são vistos como interconectados na promoção de aprendizagens. Um dos principais seriam os hinos, apontados, na maioria das vezes, como o conteúdo dos ensinos. Já a ingestão ritualística do chá, associada aos hinos, promoveriam peias, mirações ou insights. Esses seriam os aprendizados em si, apontados como a "metodologia", ou a forma como o Daime ensina. Mas as aprendizagens ocorrem, segundo os entrevistados, não só dentro dos trabalhos, mas também pela vivência com a comunidade daimista.

Conjuntamente com a comunidade foi alocada a percepção difundida entre os colaboradores de que, além do Daime, se aprende com a vida, ou seja, de que estamos aqui nesse mundo para aprender. Apesar de esses elementos serem aqui abordados separadamente, eles foram apontados como interconectados na construção dos saberes. Pode-se compreender, nessa pesquisa, que a educação na escola daimista é vivida através do trabalho ritual e do trabalho de transformação de si como princípios e meios educativos. Entre os frequentadores do Santo Daime, a "educação espiritual" ocorreria através do "trabalho espiritual" promovido pelo ritual.

\section{REFERÊNCIAS}

ABEL, Marcos Chedid. O insight na psicanálise. Psicologia, Ciência e Profissão, 2003, 23 (4), p. 22-31. 
ALBUQUERQUE, Maria Betânia Barbosa. Pedagogia da floresta: um estudo sobre práticas educativas centradas no culto ao Santo Daime. Anais do VI Congresso Luso Brasileiro de História da Educação. Percursos e Desafios da pesquisa e do ensino de história da Educação. Uberlândia - MG, 2006. p. 4923-4934.

ALBUQUERQUE, Maria Betânia Barbosa. Filosofia, educação e religião: conexões a partir do Santo Daime. Anais do $18^{\circ}$ Encontro de Pesquisa Educacional do Norte e Nordeste. Maceió - AL, 2007a.

ALBUQUERQUE, Maria Betânia Barbosa. Práticas educativas da religião do Santo Daime: anotações para uma história da educação não escolar. Revista Cocar, v. 1, n. 1, 2007b. p. 99-110.

ALBUQUERQUE, Maria Betânia Barbosa. Beberagens Tupinambá e processos educativos no Brasil colonial. Educação em Revista, Belo Horizonte, v. 27, n. 1, 2011 a.

ALBUQUERQUE, Maria Betânia Barbosa. Epistemologias e saberes da ayahuasca. Belém, EDUEPA, 2011b.

ALBUQUERQUE, Maria Betânia Barbosa. Educação, epistemologia e saberes na religião do Santo Daime. Anais dos Simpósios da ABHR, v. 13. São Luís, UFMA: 2012a.

ALBUQUERQUE, Maria Betânia Barbosa. Saberes da ayahuasca e processos educativos na religião do Santo Daime. Revista Latinoamericana de Ciencias Sociales, Niñes y Juventud, v. 10, n. 1, 2012b. p. 351-365.

ALBUQUERQUE, Maria Betânia Barbosa. Educação e saberes culturais: apontamentos epistemológicos. In: PACHECO, Agenor Sarraf et al. (orgs.). Pesquisas em Estudos Culturais na Amazônia: cartografias, literaturas \& saberes interculturais. Belém: Ed. AEDI, 2015. p. 651-692.

AMARAL, Maria Nazaré de Camargo. Dilthey: um conceito de vida e uma pedagogia. São Paulo: Perspectiva, 1987.

AMARAL, Maria Nazaré de Camargo. Dilthey: vivência e compreensão nas ciências do espírito. Revista do Clube Humboldt do Brasil. p. 7-32. São Paulo, nov. 2001.

BHAGAVAD GITA. Tradução de Huberto Rohden. 2. ed. São Paulo: Martin Claret, 2007.

BRANDÃO, Carlos Rodrigues. O que é educação? São Paulo: Brasiliense, 2007.

CEMIN. Arneide Bandeira. Opoder do Santo Daime: ordem, xamanismo e dádiva. São Paulo: Terceira Margem, 2001.

CHAMORRO, Graciela. Terra madura Yvy Araguyje: fundamento da palavra Guarani. Dourados, Mato Grosso do Sul: Ed. UFGD, 2008.

DEWEY, John. Democracia e educação - introdução à filosofia da educação. 3. ed. São Paulo: Companhia Editora Nacional, 1959.

DEWEY, John. Experiência e educação. 2. ed. São Paulo: Companhia Editora Nacional, 1976.

DIAS JUNIOR, Walter. O império de Juramidam nas batalhas do astral: uma cartografia do imaginário no culto ao Santo Daime. Dissertação (Mestrado em Ciências Sociais) - Pontifícia Universidade Católica de São Paulo, São Paulo, 1992.

FERNANDES, Vera Fróes. A história do povo Juramidam: introdução a cultura do Santo Daime. Manaus: SUFRAMA, 1986.

FRANCA, Filipe Starling Loureiro. Os sentidos da experiência com a ayahuasca: uma leitura fenomenológica. Dissertação (Mestrado em Psicologia) - Universidade Católica de Brasília, Brasília, 2011.

FRANZ, Marie-Louise. O processo de individuação. In: JUNG, Carl Gustav (org.). O homem e seus simbolos. 2. ed. especial. Rio de Janeiro: Nova Fronteira, 2008. 
GOULART, Sandra Lúcia. Raízes culturais do Santo Daime. Dissertação (Mestrado em Antropologia Social) - Universidade de São Paulo, São Paulo, 1996.

GOULART, Sandra Lúcia. Contrastes e continuidades em uma tradição Amazônica: as religiões da ayahuasca. Tese (Doutorado em Ciências Sociais) - Universidade Estadual de Campinas - São Paulo, 2004.

GROISMAN, Alberto. Eu venho da floresta: um estudo simbólico sobre o contexto do Santo Daime. Florianópolis: Ed. UFSC, 1999.

GUERRERO ARIAS, Patricio. Corazonar desde el calor de las sabidurías insurgentes la frialdad de la teoría y la metodologia. Sophia: Colección de Filosofia de la Educación: Universidad Politécnica Salesiana del Ecuador, n. 13, p. 199-228, 2012.

HILLMAN, James. O código do ser. Uma busca do caráter e da vocação pessoal. Rio de Janeiro: Objetiva, 2001.

JUNG, Carl Gustav. A prática da psicoterapia. In. Obras completas de C. G. Jung (v. 16). Rio de Janeiro: Vozes, 1987.

KAHMANN, Ana Paula; SILVEIRA, Éder da Silva. Educação no Santo Daime e as culturas do ser e do estar. Revista Cocar (online), v. 11, p. 413-443, 2017.

$\mathrm{KUSCH}$, Rodolfo. El pensamiento indígena y popular en América. In: KUSCH, Rodolfo. Obras completas. Tomo II. Rosario: Fundación A. Ross, 2000.

LABATE, Beatriz Caiuby. A reinvenção do uso da ayabuasca nos centros urbanos. Campinas, São Paulo: Mercado de Letras, 2004.

LIMA, Sérgio Alex Silva. Experiências e símbolos de transformação na doutrina da floresta. Dissertação (Mestrado em Ciências da Religião) - Universidade Federal de Juiz de Fora, Juiz de Fora - Minas Gerais, 2005.

LUNA, Luis Eduardo. Narrativas da alteridade: a ayahuasca e o motivo de transformação em animal. In: LABATE, Beatriz Cauiby; GOULART, Sandra Lúcia (orgs.). O uso ritual das plantas de poder. Campinas, São Paulo: Mercado de Letras, 2005.

MACRAE, Edward. Guiado pela lua: xamanismo e uso ritual da ayahuasca no culto do Santo Daime. 1. ed. São Paulo: Ed. Brasiliense, 1992.

OLIVEIRA, José Erivan Bezerra de. Santo Daime, o professor dos professores: a transmissão do conhecimento através dos hinos. Tese (Doutorado em Sociologia) - Universidade Federal do Ceará, Fortaleza - Ceará, 2008.

PELAEZ, Maria Cristina. Santo Daime, transcendência e cura: interpretações sobre as possibilidades terapêuticas da bebida ritual. In: LABATE, Beatriz Cauiby; ARAÚJO, Wladimir Sena (orgs.). O uso ritual da ayahuasca. 2. ed. Campinas, São Paulo: Mercado de Letras; São Paulo: FAPESP, 2004.

REHEN, Lucas Kastrup Fonseca. Recebido e ofertado: a natureza dos hinos na religião do Santo Daime. Dissertação (Mestrado em Antropologia) - Universidade do Estado do Rio de Janeiro, Rio de Janeiro, 2007.

ROSE, Isabel Santana de. Espiritualidade, terapia e cura: um estudo sobre a expressão da experiência no Santo Daime. Dissertação (Mestrado em Antropologia Social) - Universidade Federal de Santa Catarina, Florianópolis, 2005.

SCHULTES, Richard Evans. An overview of hallucinogens in the Western hemisphere en Flesh of the Gods: Ritual Use of Hallucinogens, de FURST, P. NY (ed.). Praeger, 1972. 
SILVA, Clodomir Monteiro da. O Palácio de Juramidam - Santo Daime: um ritual de transcendência e despoluição. Dissertação (Mestrado em Antropologia Cultural) - Universidade Federal de Pernambuco, Recife, 1983.

SILVA, Leandro Okamoto da. Marachimbé chegon foi para apurar. estudo sobre castigo simbólico, ou peia, no culto do Santo Daime. Dissertação (Mestrado em Ciências da Religião) - Pontifícia Universidade Católica de São Paulo, São Paulo, 2004.

TAVARES, Zélia Regina Corrêa. A ayahuasca como um veículo para a expansão da consciência - uma experiência na busca da transformação pessoal. Monografia (Graduação em Psicologia) - Centro Universitário de Brasília, Brasília, 2005.

VERGUEIRO, Paola Vieitas. Jung, entrelinhas: reflexões sobre os fundamentos da teoria junguiana com base no estudo do tema da individuação em Cartas. Psicologia: teoria e prática, São Paulo, v. 10, n. 1, jun. 2008.

Submetido em setembro de 2019 Aprovado em marco de 2020

\section{Informações do(a)(s) autor(a)(es)}

Ana Paula Kahmann

Universidade de Santa Cruz do Sul - UNISC

E-mail:ana.kahmann@hotmail.com

ORCID: https://orcid.org/0000-0002-1927-9094

Link Lattes: http://lattes.cnpq.br/9384093383952211

Éder da Silva Silveira

Universidade de Santa Cruz do Sul - UNISC

E-mail: eders@unisc.br

ORCID: https://orcid.org/0000-0002-1242-2126

Link Lattes: http://lattes.cnpq.br/9314328600981486 